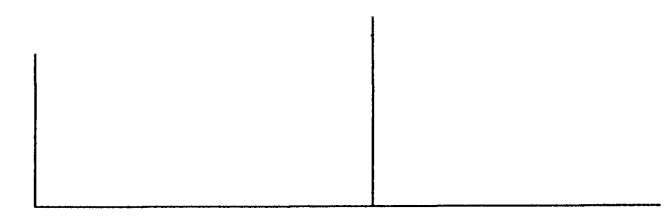

Rev. Latinoam. Psicopat. Fund., III, 4, 80-91

\title{
Ideologia e psicopatologia: uma discussão fenomenológica transcultural*
}

\author{
Virgínia Moreira
}

\begin{abstract}
Este estudo tem como objetivo discutir a relação entre ideologia e psicopatologia com base na perspectiva de homem mundano colocada pela fenomenologia de Merleau-Ponty (1964,1966,1970). Na medida em que esta entende o homem existindo em mútua constituição com o mundo, dá lugar a uma leitura da psicopatologia também como emergente em constituição com o mundo, ou a cultura (Moreira, 1993, 1999; Moreira \& Aramburú, 1999).

São examinados alguns exemplos de ideologias ou formas de pensar na cultura contemporânea que levam ao surgimento de patologias mentais, assim como pesquisas de caráter transcultural (Draguns, 1990; Cooper \& Sartorius, 1991; Schumaker, 1996) que mostram a estreita relação entre ideologia e psicopatologia além de publicações fenomenológicas sobre a relação entre psicoterapia, psicopatologia e cultura (Tatossian, 1997; Doukhan, 1998; Dörr, 1995).

Palavras-chave: Ideologia, psicopatologia, cultura contemporânea
\end{abstract}

* Conferência proferida no III Congresso sobre Mal-Estar e Subjetividade, Fortaleza, CE, 12-14 de maio de 2000. Este texto é parte do marco teórico da pesquisa Psicopatología de la vida chilena y brasileña: fenomenología clínica de la psicosis en una perspectiva transcultural, projeto DICYT n²039793MC, Universidad de Santiago de Chile. 


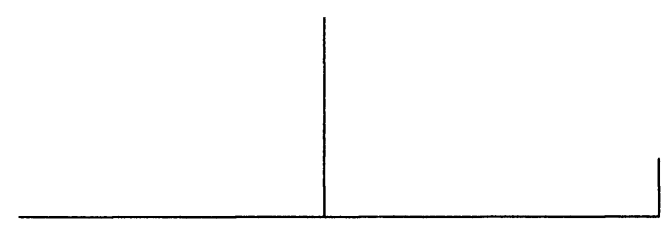

\section{Da ideologia}

O termo ideologia foi criado no final do século XVIII, por Destutt de Tracy, filósofo e economista francês, para denominar o que ele chamava ciências das idéias, definida como "... o estudo das idéias, de suas características, de suas leis, de suas relações com os signos que a representam e, sobretudo, de sua origem" (Lalande, 1985: 458-459). Os ideologistas foram um grupo filosófico e político no início do século XIX, para quem “... a ideologia ou ciência das idéias tinha uma intenção profundamente humanista de unificar o que o indivíduo pode compreender e experimentar" (Pastor, 1986: 14).

Desde então, a palavra ideologia adquiriu distintos significados ao largo da história. Sua interpretação marxista "... como pensamento teórico que crê desenvolver-se abstratamente com base em seus próprios dados, mas que é, na verdade, a expressão dos fatos sociais, particularmente dos fatos econômicos" (Lalande, 1985: 459) foi amplamente utilizada. A ideologia tomaria as idéias como independentes da realidade cultural, quando, supostamente, pretende explicá-la (Chauí, 1982). Ricoeur (1977) argumenta que ideologia é, ao mesmo tempo, interpretação do real e obturação do possível; Gramsci (1978) coloca que o significado da palavra ideologia passou de ciência das idéias a um sistema de idéias que estaria comprometido com o poder. Para Pastor (1986), no âmbito da psicologia social a ideologia seria "um conjunto de hipóteses sobre a natureza do homem, do mundo e da sociedade" (p. 17). Atualmente, a psicologia crítica trabalha sistematicamente o conceito de ideologia "como um sistema de práticas e representações que produz, mantém e reproduz relações sociais de dominação" (Sloan, 2000: 2). 


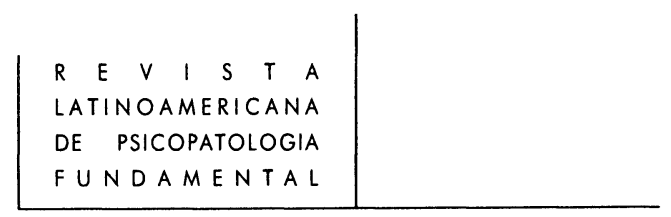

Apesar da importância histórica e ideológica desta discussão não se pretende estendê-la aqui; este estudo entende o termo ideologia desde o senso comum, definido no dicionário: um conjunto de idéias fundamentais que caracteriza o pensamento de uma pessoa; coletividade ou época.

\section{Ideologia e neurose}

A ideologia foi abordada como uma psicopatologia sociocultural pelos cientistas sociais da Escola de Frankfurt, na formulação da Teoria crítica. Tinham como objetivo desenvolver um enquadre no qual a pesquisa científica e as conseqüências políticas destas estariam unificadas, exigindo que o pesquisador tomasse uma posição perante a sociedade, em vez de ignorá-la pelo interesse de descobrir leis científicas universais. Horkheimer \& Adorno (1978) observam que, ainda que o tema da ideologia tenha se generalizado na linguagem científica, o homem contemporâneo se adapta às condições dadas em nome de um suposto realismo. Os indivíduos se veriam como peças de um jogo, mas o aceitam, se adaptam à mentira ainda que a vejam, sabem que a ideologia já não garante nada e que as coisas são como são.

Por sua vez, Habermas (1980) assinala que a ideologia impediria a tematização dos fundamentos do poder e a abertura do discurso prático, excluindo da comunicação temas inconvenientes para o sistema de poder, que seriam então censurados, retirados da linguagem, transferidos para o inconsciente. Seu ponto de vista focaliza fundamentalmente as distorções da comunicação que caracterizam o mundo contemporâneo, dando lugar à falsa consciência. Para Habermas (1970, 1979) o tipo de comunicação existente entre o paciente e o psicoterapeuta (referese de forma mais específica ao analista), como modelo de comunicação, seria o mais adequado para o desenvolvimento desta, dado que as distorções ideológicas são gradualmente superadas quando as pessoas têm um desejo verdadeiro de refletir sobre a validade da estrutura no que se refere às intenções presentes no ato de falar (Wuthnow, Hunter, Bergesen \& Kurzweil, 1985).

Freitag \& Rouanet (1980) apresentam a visão de Habermas da deformação dos processos de comunicação na sociedade como análogo ao da neurose, visto que esta se caracteriza pela inibição da comunicação do sujeito consigo mesmo e com seu mundo. Poderíamos dizer, em uma linguagem mais próxima da fenomenologia, um não dar-se conta do que sente ou pensa - diria Fritz Perls, fundador da Gestalt-terapia - ou, ainda, um estado interno de incongruência -, diria Carl Rogers, no âmbito da "abordagem centrada na pessoa". Em uma linha de raciocínio psicanalítica, assim como a neurose retiraria conteúdos da linguagem, transferindo-os para o inconsciente, a comunicação na cultura contemporânea ex- 


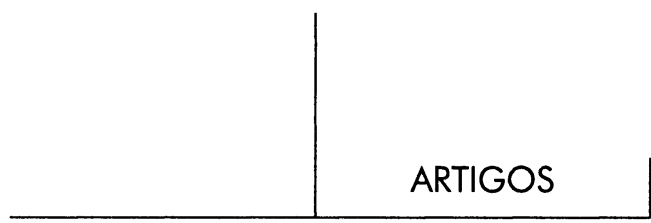

clui os termos ameaçadores à manutenção do status quo, por meio da legitimação ideológica. Para o tratamento das neuroses a psicoterapia seria uma tentativa de re-simbolizar esses conteúdos excluídos, reintegrando-os à linguagem pública. $\mathrm{O}$ neurótico se ilude, se engana a si mesmo e aos outros da mesma forma como atua a falsa consciência em relação à sociedade. Assim como a psicoterapia tem como objetivo a elucidação do si mesmo, a "teoria crítica" teria o papel de elucidação pedagógica, propondo reflexões e interpretações que levem os sujeitos imersos na falsa consciência a reconhecerem-se em tais construções por intermédio de processos autônomos de auto-reflexão.

Com base na analogia entre neurose $x$ ideologia e psicoterapia $x$ teoria crítica, chegamos ao âmbito dos fenômenos psíquicos, objetos de estudo e trabalho da psicopatologia.

\section{Homem mundano $x$ individualismo antropocêntrico}

Uma dimensão fundamental para a compreensão da relação entre ideologia, psicopatologia e cultura, foco deste estudo, será a visão de homem que lhe dá fundamento. Com este fim, vale resgatar o homem mundano proposto pela fenomenologia de Merleau-Ponty (1945). Historicamente, a fenomenologia tem por tradição a preocupação com a relação homem-mundo, desde Husserl, seu criador, pelo idealismo transcendental fenomenológico. Heidegger supera uma fenomenologia idealista quando desenvolve a idéia de mundaneidade do homem como conceito ontológico - homem como ser no mundo. O mundo é o contexto que, de fato, se vive como presença, cujo significado é pré-ontologicamente existencial em suas dimensões pública e privada (Heidegger, 1989).

A preocupação heideggeriana sobre o significado existencial do mundo se radicalizará na fenomenologia de Merleau-Ponty, para quem a vida humana se encontra envolvida no mundo sensível, na história, ou, poderíamos acrescentar, na cultura. O mundo sensível seria, então, para o filósofo francês, a extensão do homem, ou tudo o que lhe dá continuidade, existindo em mútua constituição com este. $\mathrm{O}$ homem está implicado no mundo e sua abertura a este mundo histórico não é um $a$ priori ou uma ilusão, mas uma característica inerente ao ser. Nas palavras de Merleau-Ponty (1960: 137).

... a inerência de meu pensamento a uma determinada situação histórica sua, e, através dela, a outras situações que lhe interessam - dado que é originária com respeito às relações objetivas das quais nos fala a ciência - faz do conhecimento do social um conhecimento de si mesmo, invoca e autoriza uma visão da intersubjetividade como minha que a ciência esquece... 


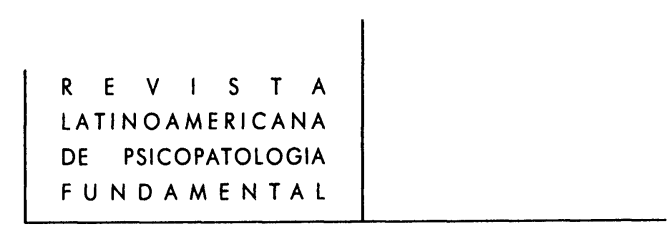

Pensando o tema homem-mundo Merleau-Ponty pretende manter-se no domínio do pensamento pré-reflexivo, desenvolvendo uma fenomenologia que, como método, se opõe radicalmente ao pensamento ocidental dualista, berço da dicotomia sujeito-objeto (Moreira, 1993, 1999). Com a visão de homem mundano, Merleau-Ponty (1960 e 1970) rompe, definitivamente, com a dicotomia homemmundo, sujeito-objeto, indivíduo-sociedade, isto é, ideologia-homem- psicopatologia-cultura se constituem mutuamente e, portanto, não faz sentido pensar estes fenômenos isoladamente, assim como é insuficiente uma visão antropocêntrica de homem-indivíduo, apesar do equívoco das várias correntes psicológicas que são, quase sempre, sustentadas por uma visão de mundo altamente individualista (Figueiredo, 1996).

O individualismo se mantém como eixo das culturas ocidentais contemporâneas, agora com um perfil narcisista:

Aparece um novo estádio do individualismo: o narcisismo designa o surgimento de um perfil inédito do indivíduo em suas relações consigo mesmo e com seu corpo, com os demais, o mundo, o tempo, no momento em que o "capitalismo" autoritário cede passagem a um capitalismo hedonista e permissivo, acaba a idade de ouro do individualismo competitivo em nível econômico, sentimental a nível doméstico, revolucionário em nível político e artístico, e se estende a um individualismo puro, desprovido dos últimos valores sociais e morais que coexistiam ainda com o reino glorioso do homo economicus, da família, da revolução e da arte; emancipada de qualquer marco transcendental, a própria esfera privada troca de sentido, exposta como está unicamente aos desejos mutáveis dos indivíduos (Lipovetsky, 1986: 50).

Esta discussão tocará bem de perto a psicopatologia, via visão de homem mundano merleau-pontyana: "como todas as grandes dicotomias, a do corpo e do espírito se diluiu; o processo de personalização e, particularmente aqui, a expansão do psicologismo, apaga as oposições e hierarquias rígidas" (Lipovetsky, 1986: 62).

Assim é que, a visão de homem mundano da fenomenologia merleau-pontyana se contrapõe ao tradicional individualismo antropocêntrico, que é parte do pensamento dualista ocidental e lugar-comum nas psicologias e no enfoque tradicional de psicopatologia. Este homem mundano, que sempre é concebido de maneira entrelaçada ao mundo, não é o centro deste mundo, já que ele o constitui tanto como o mundo o constitui, de forma tal que se não existe um centro tão pouco teria lugar o individualismo (Moreira, 1999a e b). Ao centrar-se no sujeito individual ou na psicopatologia entendida apenas individualmente, o psicólogo clínico estaria se distanciando do fenômeno em si, em sua complexidade e totalidade, ou mundaneidade, tal como se demonstrou em pesquisa anterior (Moreira, 1993). Como bem o diz Figueiredo (1996: 59), 


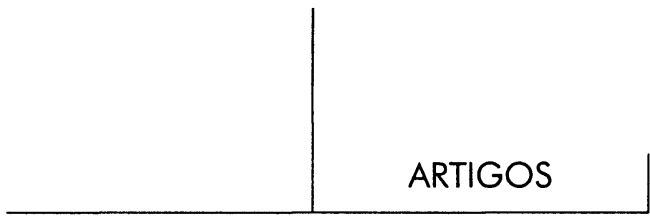

... a psicologia popularizada tem servido para sustentar a palavra de ordem "cada um na sua, pensando os seus problemas e defendendo os seus interesses e a sua felicidade". Isso poderia ser designado como hiperindividualismo e cultivá-lo é exatamente o contrário do que poderíamos esperar de qualquer psicologia científica. Essa afirmativa não parte de uma postura moral do tipo "não é direito pensarmos em nós como se fôssemos o centro do Universo". O problema é que de fato não somos, e a tarefa da ciência moderna tem sido sempre a de nos recordar que o Sol não gira em torno da Terra. Embora pareça.

Trata-se, então, de superar a ideologia individualista, que sustenta a perspectiva psicopatológica como fenômeno puramente individual (Moreira \& Aramburú, 1999), para alcançar uma abordagem desta em sua complexidade também cultural.

\section{Ideologia, psicopatologia e cultura}

Retomando a definição de ideologia como um conjunto de idéias que representa o pensamento de uma pessoa, coletividade ou época, e que existe em mútua constituição com as diferentes formas do ser-no-mundo, sadias ou psicopatológicas, é possível examinar alguns exemplos de formas de pensar na cultura contemporânea que levam ao surgimento de patologias mentais: a ideologia de que o corpo belo será necessariamente magro, se associaria a doenças como a anorexia e a bulimia diagnosticadas há cerca de 20 a 25 anos (Dörr, 1995). Até então, estas doenças, tão freqüentes no mundo contemporâneo ocidental, sequer existiam, ou pelo menos não apareciam como tal nos manuais de psicopatologia. A este respeito é interessante notar que o clássico caso de Lüdwig Binswanger (1977), Helen West, datado do início do século XX, está diagnosticado como depressão, sem nenhuma alusão ao óbvio quadro anoréxico da paciente, fato que atualmente seria identificado de imediato.

Na China, uma cultura cuja forma de pensar ou ideologia não admite a expressão pública das emoções, a depressão se manifesta prioritariamente por via somática (Draguns, 1990). Os pacientes buscam ajuda por dores de cabeça, de estômago, nas pernas ou qualquer outro tipo de queixa somática, mas um paciente chinês dificilmente terá como motivo de consulta estar deprimido. Na medida em que, como homem mundano, se constitui mutuamente com uma cultura que reprime a expressão das emoções, a manifestação da depressão também é determinada por essa mútua constituição. Quando em outras culturas contemporâneas - a brasileira, por exemplo - tornou-se quase lugar-comum na classe média alta buscar um psicólogo porque se está deprimido, o que, muitas vezes, não significa ter uma depressão, e sim, simplesmente, estar triste. 


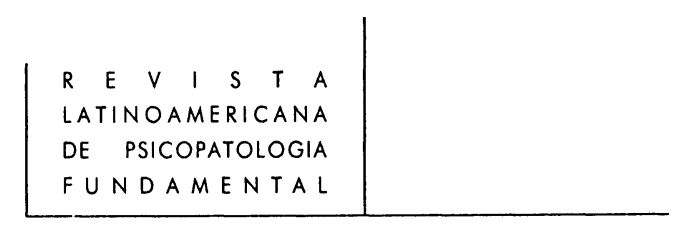

Pesquisas mostram que a depressão pós-parto, totalmente integrada na ideologia ocidental, inclusive com base em uma argumentação biológica hormonal, não existe em sociedades nas quais a responsabilidade pelo bebê não é da mãe, mas das mulheres mais velhas da comunidade (Shumaker, 1996). Nestas sociedades, quando nasce uma criança, todas as mulheres mais velhas da comunidade ou família são responsáveis por ela, ao passo que a jovem mãe deve recuperar-se do parto e aprender com a experiência das mais velhas, não tendo nenhuma responsabilidade no caso de doença ou morte do recém-nascido. Este fenômeno ocorre de maneira totalmente diversa nas sociedades ocidentais atuais, em que a mãe vive praticamente só o peso da responsabilidade do novo ser humano que ela deu à luz - o desenvolvimento sadio da criança depende em primeira instância da mãe, ainda que isso se some a outras responsabilidades como cuidar do lar, de outros filhos e, ainda, de seu próprio trabalho. No entanto, a angústia ante esta experiência, na nossa sociedade, geralmente é tratada como parte de uma depressão pós-parto, simples fruto de alterações hormonais características do período pós-parto.

$\mathrm{Na}$ França dos últimos anos têm surgido publicações fenomenológicas sobre a relação entre psicoterapia, psicopatologia e cultura (Tatossian, 1997; e Doukhan, 1998). Isto ocorre, obviamente, a partir do desmedido fenômeno social de imigração nos últimos anos, fato que não ocorria tão intensamente uma década atrás e, portanto, aspectos culturais da personalidade e da psicopatologia não eram temas prioritários de interesse por parte da maioria dos psicólogos clínicos ou psiquiatras. Com a globalização e a nova era da comunicação virtual, o mais provável é que no próximo Manual diagnóstico e estatístico (DSM) editado pela American Psychiatric Association, aparecerão categorizadas novas doenças mentais virtuais, surgidas da atual era da comunicação virtual, o que no momento não existe no atual DSM, assim como trinta anos atrás não existiam doenças tais como a bulimia ou a anorexia.

Draguns (1990) comenta pesquisas que mostram resultados importantes em estudos realizados com distintos grupos sociais de uma mesma época, mas de culturas diferentes do ponto de vista socioeconômico. Aparentemente, o grau de desenvolvimento de uma cultura seria, também, uma variável importante na constituição das várias patologias mentais. Entre estes estudos, um importante resultado foi que os pacientes pobres e de países menos desenvolvidos se recuperam mais rapidamente e em uma proporção mais alta que os de países de nível mais alto de desenvolvimento socioeconômico, o que Cooper \& Sartorius (1991) tentaram explicar, concluindo que a esquizofrenia com seus rasgos bizarros e autistas é facilitada nas sociedades industrializadas e com um estilo de vida moderno, organizadas dentro de um modelo de família nuclear. Draguns (1980) acrescenta que Torrey (1980), tomando como base as colocações de Cooper e Sartorius, retoma a controvérsia de que a esquizofrenia e a modernidade estariam conectadas ao desenvolvimento 


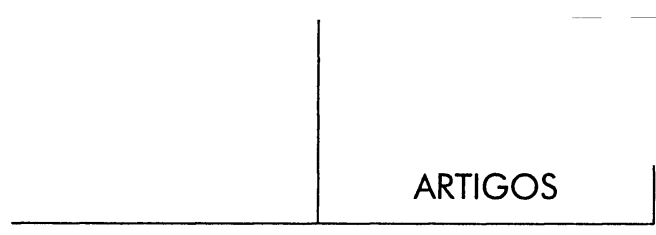

tecnológico. De fato, se acompanhamos com Foucault (1991) a história da doença mental, podemos constatar que diagnósticos de esquizofrenia, tanto como outros diagnósticos de doenças mentais são relativamente recentes na história; se antes estas formas de estar humano existiam, não eram diagnosticados, já que não faziam parte do domínio médico. Sabemos que na Idade Média as alucinações, por exemplo, não eram entendidas como doença mental e sim indicavam que o indivíduo estava possuído por forças do mal; assim tais fenômenos eram parte do domínio teológico e a religião se ocupava deles.

Segundo Schumaker (1996), pesquisadores transculturais começaram a explorar e a definir os limites das formulações teóricas de psicopatologia quando estas deixam de integrar os fatores culturais, já que, como assinalam Tseng \& McDermott (1981, apud Schumaker, 1996), a perspectiva cultural oferece várias vantagens em relação a uma visão que concentra apenas no individual, o que, como vimos, faz parte da tradição psicológica (Moreira, 1999a; e Figueiredo, 1996). Jenkins (1994, apud Schumaker, 1996), assinala que a psicopatologia, como manifestação, pode ser simultaneamente relevante em uma cultura e totalmente irrelevante em outras.

Em particular, duas tendências teóricas emergiram nos últimos anos, relacionadas com as iniciativas de pesquisa. Uma destas tendências foi o rápido crescimento em popularidade da psicologia clínica cognitiva, na qual a psicopatologia é vista como uma conseqüência de processos mentais, operando amplamente no plano individual. Uma outra tendência foi o pronunciado direcionamento aos modelos biológicos de psicopatologia, que, por sua vez, gozam de considerável suporte em pesquisas que utilizam sempre tecnologia mais sofisticada. Por exemplo, a evidência implicou fatores biológicos e genéticos em um bom número de doenças mentais, incluindo esquizofrenia, depressão unipolar e bipolar, desordens de ansiedade tais como desordem de pânico, desordem obsessivo-compulsivo, desordem anti-social de personalidade e outras desordens relacionadas a estas (Schumaker, 1996: 180-181).

No caso da depressão, existe uma longa evidência com relação à interação entre depressão e cultura, o que foi demonstrado claramente nas pesquisas de Aldwin \& Greenber (1987, apud Schumaker, 1996) e Jenkins, Kleiman \& Good (1991, apud Schumaker, 1996). Quando a depressão aparece em sociedades não ocidentais, seu modo de expressão é bastante diferente do ocidental, como foi assinalado anteriormente, com sintomas de natureza somáticos (Kirmayer, 1985; Kleinman, 1988, apud Schumaker, 1996). Estas conclusões instigam a discussão sobre os critérios para o estabelecimento do diagnóstico da depressão, em meio à diversidade de seus modos de expressão. $O$ fato de que nas culturas não-ocidentais a cognição, que caracteriza a depressão (culpa, falta de esperanças, tristeza etc.), está geralmente ausente, leva a pôr em dúvida se o diagnóstico de depressão 


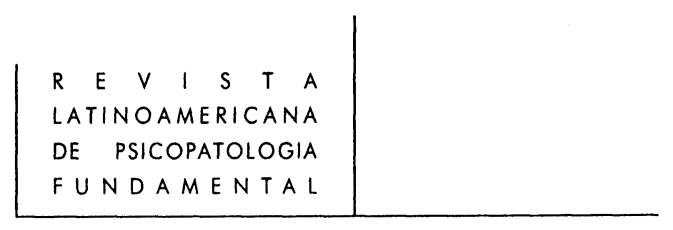

é realmente apropriado (Draguns, 1990). Ainda assim se reconhece que a interação significativa entre cultura e psicopatologia são muito bem ilustradas por meio da depressão, uma categoria de distúrbio mental que já atraiu prioritariamente explicações etiológicas de base biológico-individual. Em particular, estas explicações se focalizavam em fatores biológicos e/ou cognitivos. Estes modelos foram seriamente questionados, uma vez que perspectivas transculturais foram introduzidas (Schumaker, 1996).

Outros autores destacam a importância de considerar as diferenças nos processos de medida nas pesquisas transculturais, em virtude da tendência a ocupar instrumentos validados no Ocidente, que não integrariam ditas diferenças. Crittenden e outros colocam, finalmente, que para conseguir uma maior especificação quanto às manifestações somáticas da depressão se requer ter uma maior compreensão dos sintomas (Schumaker, 1996). Podemos dizer que isto ocorre na medida em que se tome uma perspectiva fenomenológica merleau-pontyana, na qual os sintomas seriam entendidos na mútua constituição entre homem e mundo, ou entrelaçados a este. Esta pequena revisão bibliográfica de estudos transculturais da psicopatologia mostram a relevância de uma perspectiva fenomenológica para a compreensão da psicopatologia entendida como constituída mutuamente com a ideologia e a cultura.

\section{Conclusão}

As pesquisas atuais sobre psicopatologia em uma perspectiva transcultural são escassas e quase inexistem na América Latina. No entanto, além das pesquisas já mencionadas, não se pode, sobretudo, esquecer os estudos desenvolvidos por Sartorius, Jablensky, Korten \& Erneber (Schumaker, 1996) sobre a esquizofrenia e a depressão, financiados pela Organização Mundial da Saúde durante quase toda a década de 1970 e início da de 1980 . A conclusão das pesquisas sobre estes dois tipos de doenças mentais mostra que a psicopatologia tem tanto características universais como culturais. Observações e comparações transculturais mostram uma perspectiva dos esforços mais recentes para compreender a psicopatologia, isto é, compreendê-la como fenômeno mundano, que se constitui mutuamente com cada mundo ou cada cultura específica. Nas palavras de Schumaker (1996: 190) “... em contraste com a idéia de que a cognição opera em nível individual, observações culturais levam a reconhecer que cognições 'pessoais' ou privadas estão profundamente enraizadas na fábrica da cultura". Desde uma perspectiva fenomenológica, se trata, então, de desenvolver uma leitura da psicopatologia que enxergue, entre outras, a dimensão cultural de sua constituição. 


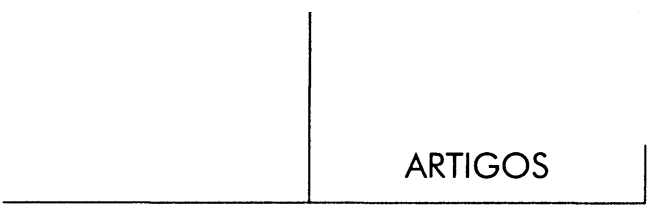

Referências Bibliográficas

Binswanger, L. El caso de Helen Westt. In May, R.; Angel, E. y Ellenberger, H. Existencia: nueva dimensión en psiquiatría y psicologia. Madrid: Gredos, 1977. Chauí, M. O que é ideologia. São Paulo: Brasiliense, 1982. (Primeiros Passos).

DörR, O. Psiquiatría antropológica. Santiago: Editorial Universitária, 1995.

DRAGUNS, J. Applications of cross-cultural psychology in the field of mental health. In R. W. Brilin (Ed.). Applied crosss-cultural psychology. Newbury Park, CA: Sage, 1990.

Doukhan, F. Cultures et rélations thérapeutiques. Sur \& Nord: folies \& cultures, 9, 127-132, 1998.

Figueiredo, L. C. Psicologia: uma introdução. São Paulo: Educ, 1996.

Freitag, B. \& Rouanet, S. Habermas: sociologia. São Paulo: Ática, 1980.

Gramscl, A. Obras escolhidas. São Paulo: Martins Fontes, 1978.

HABERMAS, J. On systematically distorted communication. Inquiry, 13, 205-218, 1970.

Communication and the Evolution of Society. Boston: Beacon, 1979.

Introducción. In FreitaG, B. \& RouAnet, S. Habermas: sociologia. São Paulo: Ática, 1980.

HeidegGer, M. Ser e tempo. Petrópolis: Vozes, 1989. v. II.

Horkheimer, M. \& Adorno, T. Temas básicos da sociologia. São Paulo: Cultrix, 1978.

Lalande, A. Vocabulaire technique et critique de la philosophie. Paris: Presses Universitaires de France, 1985.

LiPOVETSKy, G. La era del vacío. Barcelona: Anagrama, 1986.

Merleau-Ponty, M. Signes. Paris: Gallimard, 1960.

L'oeil et l'esprit. Paris: Gallimard, 1964.

La doute de Cézanne. In Merleau-Ponty, M. Sens et non sens. Paris: Nagel, 1966.

Lo visible y lo invisible. Barcelona: Seix Barral, 1970.

Moreira, V. O homem "mundano" na fenomenologia. Insight-Psicoterapia, 32, 2324, 1993a.

Beyond the person: Merleau-Ponty 's concept of "flesh" as (re)defining Carl Rogers Person Centered Theory. The Humanistic Psychologist, 21, 138-157, 1993b.

Psicoterapia centrada na pessoa e fenomenologia. Psicologia: Teoria e Pesquisa. v. 9, n. 1, p. 157-172, 1993c.

Bases epistemológicas de la psicología humanista. Revista de la Facultad de Humanidades, Universidad de Santiago de Chile. v. 4, n. 4, p. 87-96, 1999a. 


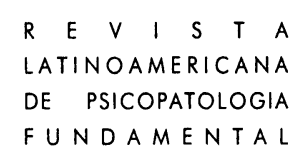

Modos de constitución de la subjetividad: una perspectiva fenomenológica transcultural. Psykhe. v. 8, n.1, p. 27-31, 1999b.

\& ARAmburú, B. (1999). ¿Psicopatología(s)?. Hacia una comprensión histórico-cultural. Revista Terapia Psicológica, v. 7, n.1, 1999 (En prensa.)

PASTOR, G. Ideologías: su medición psicosocial. Barcelona: Herder, 1986.

Ricouer, P. Interpretação e ideologia. Rio de Janeiro: Francisco Alves, 1974.

SLOAN, T. Psychological resistance to de-ideologization. http://www. personal.utulsa.edu/ tod-sloan/deideologization.htm. 17/3/2000.

Schumaker, J. Understanding Psychopatology Lessons from the developing World. In Psychology and Developing World. Connecticut: Praeger, 1996.

Tatossian, A. (1997). Psychiatrie phénomenologique. Paris: ETIM, 1997.

Wuthnow, R.; Hunter, J.; Bergesen, A. \& Kurzweil, E. Cultural analysis. London:

Routledge \& Kegan Paul, 1985.

\section{Resumos}

Este estudio tiene como objetivo discutir la relación entre psicopatología y cultura, a partir de la perspectiva de hombre mundano planteada en la fenomenología de Merleau-Ponty $(1964,1966,1970)$. Dado que esta entiende al hombre existiendo en mútua constitución com el mundo, dá lugar a una lectura de la psicopatología también como emergente en mútua constitución com el mondo, o la cultura (Moreira, 1993, 1999; Moreira \& Aramburú, 1999)

Se examinan algunos ejemplos de ideologías o formas de pensar en la cultura contemporánea, que llevan al surgimiento de patologías mentales, asi como investigaciones de carácter transcultural (Draguns, 1990; Cooper \& Sartorius, 1991; Shumaker, 1996) que muestran la estrecha relación entre ideología y psicopatología, además de publicaciones fenomenológicas sobre la relación entre psicoterapia, psicopatología y cultura (Tatossian, 1997, Doukhan, 1998, Dörr, 1995).

Palabras llave: Ideología, psicopatología, cultura contemporánea

Cet étude a comme bût de discuter la relatión entre la psychopathologie et la culture, à partir de la visión d'homme mondain, postulé par la phénomenologie de Merleau-Ponty (1964, 1966, 1970). En comprennat à l'homme comme existant en constitution réciproque avec le monde, cette ci donne lieu a une lecture de la psychopathologie aussi comme emergeant en constitutión réciproque avec le monde ou la culture (Moreira, 1993, 1999; Moreira \& Aramburú, 1999).

On examine quelques exemples de idéologies ou de formes de pensée dans la culture contemporaine, qui ammenent a des pathologies mentales, aussi que des recherches trans-cultures (Draguns, 1990 ; Cooper \& Sartorius, 1991 ; Schumaker, 1996) qui montrent la importante rélation entre idéologie et culture, et, finalement, 


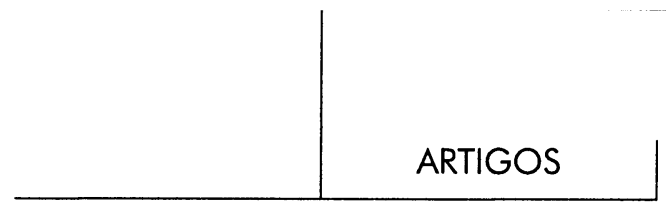

des publications phénomenologiques sur la relation entre psycothérapie, psychopathologie et culture (Tatossian, 1997, Doukhan, 1998, Dörr, 1995).

Mots clés: Idéologies, psychopathologie, culture contemporaine

This study aims at discussing the relationship between ideology and psychopathology starting from of mundane man's perspective placed by the phenomenology of Merleau-Ponty (1964,1966,1970). As it understands man existing in mutual constitution with the world, it also gives place to a reading of psychopathology as emergent in constitution with the world, or the culture (Moreira, 1993, 1999; Moreira \& Aramburú, 1999).

Some examples of ideologies are examined or forms of thinking in the contemporary culture that leads to the emergence of mental pathologies, as well as cross-cultural inquiries (Draguns, 1990; Cooper \& Sartorius, 1991; Schumaker, 1996) that shows the narrow relationship between ideology and psychopathology besides phenomenological publications about the relationship among psychotherapy, psychopathology and culture (Tatossian, 1997, Doukhan, 1998; Dörr, 1995).

Key words: Ideology, psychopathology, contemporary culture

Versão inicial recebida em julho de 2000.

Versão revisada recebida em novembro de 2000. 